\title{
NOVEL MOORING DESIGN OPTIONS FOR HIGH-INTENSITY TYPHOON CONDITIONS - AN INVESTIGATION FOR WAVE ENERGY IN CHINA
}

\author{
P R Thies ${ }^{{ }^{1}}$, S Crowley ${ }^{1}$, L Johanning ${ }^{1}$, W Micklethwaite, $\mathrm{H} \mathrm{Ye}^{2}$, D Tang ${ }^{2}, \mathrm{~L} \mathrm{Cui}^{3}$ and $\mathrm{X} \mathrm{Li}^{3}$ \\ ${ }^{1}$ University of Exeter, UK \\ ${ }^{2}$ South China Sea Institute of Oceanology (SCSIO), China \\ ${ }^{3}$ National Ocean Technology Centre (NOTC), China
}

\section{SUMMARY}

The industrialised and densely populated coastal regions in China are in search of local energy supplies in order to avoid expensive energy transmission from the West of China. Wave energy technology is considered as one of the possible solutions with a potential installed capacity of $13 \mathrm{GW}$ around China. However, typhoons are a major meteorological threat for China's coastal regions with estimated damages of over 20bnRMB. Prediction, prevention and mitigation of typhoons have greatly improved and coastal regions at risk are readily identified.

This paper will outline the environmental load conditions that are faced by floating installations in the Chinese Sea. The paper assesses the feasibility of novel mooring solutions that aim to absorb energy during the most severe load conditions in order to reduce peak and fatigue loads. Their suitability for wave energy converters in high-intensity typhoon conditions is assessed by a fully-coupled hydrodynamic analysis. Initial modelling has been conducted in the time-domain employing a moored cylindrical buoy with six degrees of freedom. The mooring line properties have been chosen to be characteristic of the strongly nonlinear behaviour of novel mooring designs. The results show a reduction in peak loads along the entire length of the mooring line in comparison to standard rope mooring, whilst crucially not restricting the heave motion of the buoy. These initial results will inform the refinement and optimisation of the mooring design of floating installations for high-intensity typhoon conditions.

\section{INTRODUCTION}

Many of China's largest cities, including Shanghai, Tianjin and Hangzhou, are situated on China's east coast, producing $70 \%$ of the country's GDP and being responsible for more than half of the country's energy consumption. However further development in this region is restricted by a shortfall in meeting power supply demands [1]. Harnessing energy from the ocean provides a possible solution to this; the China Sea has the potential to contribute up to $12.9 \mathrm{GW}$ of installed power [2], and thus avoiding the expensive transmission of energy from the west of China. Furthermore, there are over 400 inhabited islands off the coast of China the majority of which currently lack electricity and a reliable source of fresh water. The energy demands of these remote islands could conceivably be met with the installations of localised wave power stations such as the shoreline OWC installed on Dawanshan Island [3].

However, despite China having a moderate wave energy density ranging from $2-16 \mathrm{~kW} / \mathrm{m}$, the North West Pacific experiences on average 17 typhoons per year [4], which generate extreme wind and wave conditions with the potential to destroy offshore structures, ships and coastal infrastructure. Such extreme wave climates caused by typhoons pose a threat to the reliability and survivability of wave energy converters (WECs). Typhoon Saomai in 2006, for example, had a maximum sustained wind speed of $75.8 \mathrm{~m} / \mathrm{s}$, generated $3.76 \mathrm{~m}$ high surges and $7 \mathrm{~m}$ waves causing widespread damage both on and offshore, sinking 952 ships and damaging 1,594 others moored in Shacheng harbour [5].
This paper aims to address the survivability of wave energy converters in Chinese waters during these recurring high intensity typhoons; exploring the development of suitable and reliable, yet cost-effective mooring systems.

The paper is structured as follows: the wave energy resource available in Chinese waters is briefly described in section 1.1, before considering the frequency, intensity and distribution of tropical cyclones in the region. In section 2 reported design conditions for floating offshore structures subject to typhoon conditions will be considered. In section 3, a brief review of current WEC development in China is given. Section 4 introduces the numerical model, including the characteristic nonlinear load response of novel mooring components. Results from some initial modelling are also presented and described. Section 5 concludes with the main findings and discusses aspects for further work.

\subsection{WAVE ENERGY RESOURCE}

The wave energy density in Chinese waters has significant seasonal and regional variations. Larger wind and wave energy densities are measured during the winter months, however extreme sea states occur mostly during July to October due to the conditions generated by passing typhoons. Regionally, the northern South China Sea, in particular the Luzon Strait waters, has the greatest wave energy density $10-16 \mathrm{~kW} / \mathrm{m}$, compared to the Bohai sea with an annual average wave energy density below 2 $\mathrm{kW} / \mathrm{m}[6]$, as shown in Fig. 1. 


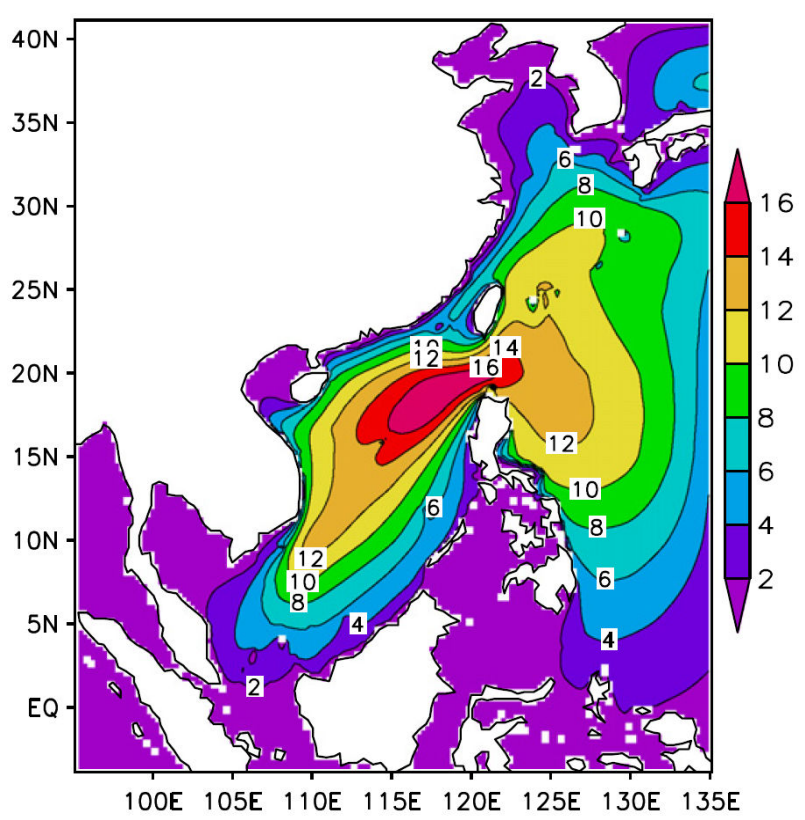

Figure 1: Annual average wave energy density in the China Sea $(\mathrm{kW} / \mathrm{m})$, Zheng et al, 2013 [6].

Wu et al [7] assess the wave energy resource in the East China Sea using data gathered from six wave buoys at water depths from 49 to $193 \mathrm{~m}$, over a three year period. The most dominant sea state to provide useful sufficient energy density levels is identified at energy periods $\mathrm{T}_{\mathrm{e}}=6-8 \mathrm{~s}$ with significant wave heights $\mathrm{H}_{\mathrm{s}}=1.5-3.5 \mathrm{~m}$. The annual mean power at the six different sites ranged between $10-15 \mathrm{~kW} / \mathrm{m}$. During the period of interest, 18 typhoons occurred in the East China Sea; extreme significant wave heights of more than $10 \mathrm{~m}$ were measured at one of the buoy stations, resulting in an estimated wave power of over $700 \mathrm{~kW} / \mathrm{m}$ per unit width wave crest. The authors [7] note that although the sea states associated with typhoon events, with the highest wave heights and thus power values, provide a notable contribution to the monthly mean statistics they make only a small impact on the total annual wave energy due to their relative low incidence.

From a design perspective however, these wave conditions are a formidable challenge, as extreme conditions, governing the survivability requirements for WECs, are a factor 50-70 larger than given operational conditions. In comparison, Wave Hub, a pre-commercial test site in the UK [8] has a ratio $\mathrm{H}_{\mathrm{s} \text {,extreme }} / \mathrm{H}_{\mathrm{s} \text {,operational }}$ of approximately 35 .

\subsection{TYPHOON EVENTS}

A typhoon is the regionally specific name for a mature tropical cyclone that develops in the North West Pacific Ocean. A tropical cyclone denotes a low pressure system over tropical or sub-tropical waters (between $5^{\circ}$ and $30^{\circ}$ latitude), and characterised by a spiral arrangement of thunderstorm activity and low level rotating winds. They require warm, moist air and sea temperatures of at least $26.5^{\circ} \mathrm{C}$ to depth of at least $50 \mathrm{~m}$ to form. The system is typically 5-6 miles high and 300-400 miles wide; on average the storms move at speeds of $4.5-7 \mathrm{~m} / \mathrm{s}$, but can travel up to $18 \mathrm{~m} / \mathrm{s}$. The strength of the winds generated by the cyclone is used to define the intensity of the storm. Table 1 summarises the classification of the intensity of tropical cyclones according to the SaffirSimpson Scale, based on the maximum 1-minute mean sustained wind speed. When the wind speed reaches $33 \mathrm{~m} / \mathrm{s}$ the tropical cyclone is called a typhoon. According to data from the JTWC, for the period 1959-2013 the North West Pacific experienced 1471 tropical cyclones, of which approximately $63 \%$ became typhoons - an average of 17 per year [4].

\begin{tabular}{|c|c|}
\hline Saffir-Simpson Scale & Max. sustained wind speed [m/s] \\
\hline Tropical Depression & $<17$ \\
\hline Tropical Storm & $18-32$ \\
\hline Category 1 Typhoon & $33-42$ \\
\hline Category 2 Typhoon & $43-49$ \\
\hline Category 3 Typhoon & $50-58$ \\
\hline Category 4 Typhoon & $58-70$ \\
\hline Category 5 Typhoon & $>70$ \\
\hline
\end{tabular}

Table 1: Classification of the intensity of tropical cyclones according to the Saffir-Simpson Scale

Typhoons typically generate high waves, storm surges and heavy rain, in addition to strong winds which induce an increase and change of direction of absolute geostrophic currents, At least $30 \%$ of tropical cyclones make landfall over one of China's coastal provinces, making these areas particularly vulnerable to severe flooding. Due to the devastation that typhoons have the potential to induce, much research has been conducted to assess and minimise the risk posed to coastal infrastructure, ships and offshore structures, see [5, 9]. In addition to these physical effects, typhoons also have a large ecological impact; tropical cyclone induced winds can cause entrainment, strong vertical mixing, and upwelling. Tropical cyclones can enhance dissolved oxygen and sea-air $\mathrm{CO}_{2}$ exchange, decrease sea surface and water column temperature, induce surface and subsurface chlorophyll a blooms, change the community structure of phytoplankton and zooplankton, and the fish abundance, see for example [10].

Zheng et al [11] analyse the available best track tropical cyclone data to find the distribution of the intensity and frequency of tropical cyclones over the China Sea. According to their results, the western North Pacific east of the Philippines and the northern South China Sea are impacted by the most tropical cyclones; the east of the Philippines suffer from the highest frequency of extreme intensity typhoons whereas lower intensity tropical storms and typhoons have the highest occurrence in the South China Sea. 


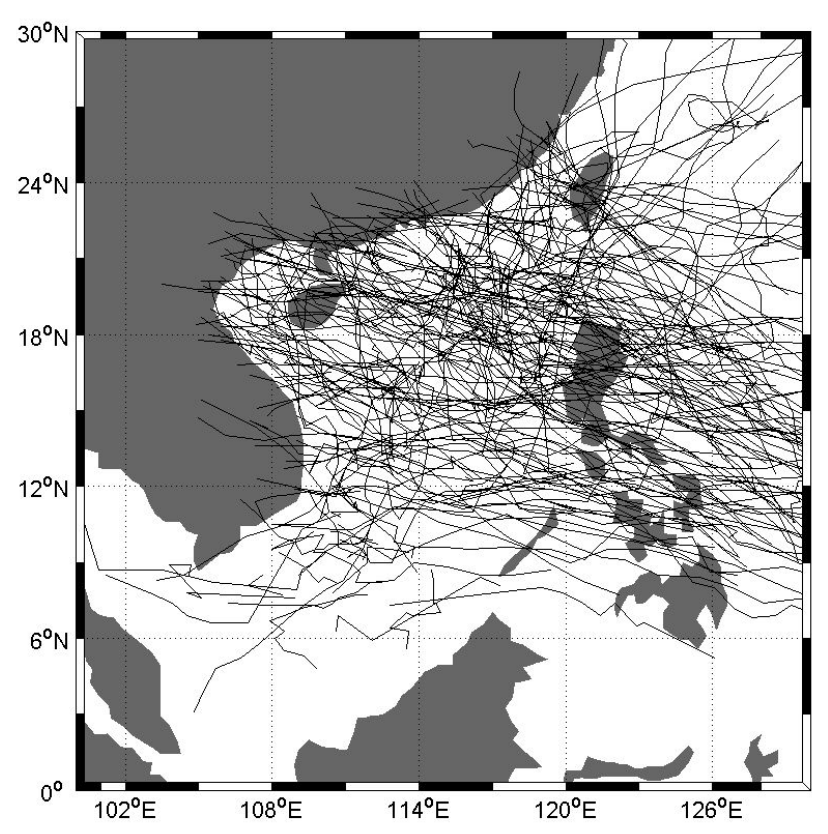

Figure 2: Typhoon tracks in the South China Sea from 1998-2014. Data from the JTWC [4].

The South China Sea alone suffers from an average of 10.8 typhoons annually [12]. The main typhoon season occurs from June to November, with the highest frequency during September. The typhoon tracks are mostly in the westward direction over the northern South China Sea with the most severe typhoons in the region reaching wind speeds of $70 \mathrm{~m} / \mathrm{s}$.

Fig. 2 illustrates the tracks of typhoons passing through the South China Sea from 1998 - 2014, suggesting that in Southern China, most tropical cyclones strike the coast from the south and southeast. A higher density of crossing typhoon tracks can be seen in the northern South China Sea, in agreement with the results of Zheng et al [11].

The number of tropical cyclones in the South China Sea during the period 1970-2012, as classified by the SaffirSimpson scale, are shown in Fig. 3. Similarly in agreement with [11], it is clear that on average the South China Sea is impacted annually by a larger number of lower intensity tropical cyclones (including tropical depressions, tropical storms and category 1 typhoons) than higher intensity events.

Although the intensity (maximum sustained wind speed) of a tropical cyclone is one metric to consider when assessing the potential survivability of an offshore structure in a given region, other factors to take into account are the significant wave height and the expected spring tide height in conjunction with changes in water depth due to storm surges [5]. A detailed assessment would also require the quantification of how stationary the typhoon may be over time.

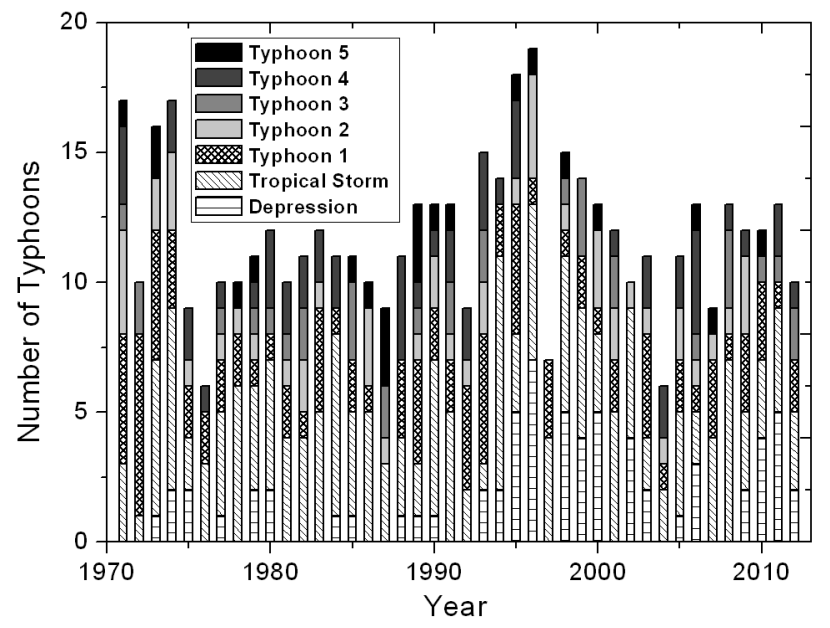

Figure 3: Number of typhoons in the South China Sea from 1970 to 2012, classified by the Saffir-Simpson scale

\section{DESIGN CONDITIONS FOR FLOATING STRUCTURES IN TYPHOON CONDITIONS}

Knowledge and experience gained through the installation and mooring of other offshore structures in regions subject to typhoons may be used to inform the mooring design requirements for wave energy converters in Chinese waters. A review of mooring system for WECs, identifying existing components from the offshore industry that have been adopted by the wave energy developers is given in [13]. Existing standards for the station keeping of offshore structures could be employed; however these do not make any allowance for the responsive and compliant mooring system requirements needed to enhance the operational performance of WECs.

The offshore wind energy industry has assessed the resistance of offshore wind farms to typhoons, and the associated design requirements. This is presently most relevant in Japan, as $85 \%$ of its wind power capacity is located offshore, largely in water depths greater than $100 \mathrm{~m}$, necessitating floating offshore wind installations. Floating technology however is still only emerging in the offshore wind industry, in comparison to fixed foundation technology, and is not yet commercially viable. The most promising structures have been modified from concepts used within the oil and gas industry, and can be classified into: spar buoy, semisubmersible platform and tension leg platform. As a result, the development of mooring and anchoring systems that can withstand the high loads that will be experienced during extreme storm conditions has been highlighted as critical [14].

Utsunomiya et al [15] report on the testing of a full and half-scale spar-type floating offshore wind turbine $1 \mathrm{~km}$ offshore from Kabashima Island, Japan. The half scale model was installed in June 2012 and subsequently attacked by the most severe typhoon worldwide of 2012, typhoon Sanba. The wind turbine survived, withstanding a maximum 10-minute average wind speed of $36.8 \mathrm{~m} / \mathrm{s}$ 
and maximum significant wave height of $9.5 \mathrm{~m}$. The maximum significant wave height was $0.9 \mathrm{~m}$ greater than the design wave height, but the maximum wind speed was $24 \%$ lower than the design wind speed.

The safe mooring of floating production, storage and offloading (FPSO) units is of importance to the offshore oil and gas industry; used since the 1970s FPSOs provide a solution to the drilling and processing of hydrocarbons in remote or deep water locations as they do not require a pipeline infrastructure for transportation. Liu et al explore the design of a reliable internal turret mooring system of a floating production, storage and offloading (FPSO) unit in the South China Sea [16]. FPSO's are typically turret moored permanently to a designated position such that they can weathervane to the direction of least resistance to wind, wave and current forcing. Statistical analysis of the environmental conditions induced by typhoons suggests that the 100 -year return maximum wave height has increased by $5 \%$ in the last few years. Furthermore, operational records of the mooring of FPSOs in the South China Sea suggest that the extreme environmental design conditions are sometimes below the actual measured environmental conditions. Hence, Liu et al [16] use 500-year return typhoon conditions to determine the required design parameters; the maximum significant wave height is predicted to be $12.4 \mathrm{~m}$. It was concluded, after consideration of factors such as of cost, reliability, operational convenience and ease of offshore installation, that a permanent internal turret mooring system with the functionality to disconnect the mooring lines, risers and power cables from the main system via a buoy during typhoon events is favourable over a fixed permanent mooring system, or a less resistant single point mooring with a quick disconnection device.

Zhao et al. also consider the mooring of FPSOs. Using measurements of the motion of the turret moored FENJIN FPSO unit obtained whilst deployed in the South China Sea along with the corresponding environmental conditions, Zhao et al analyse the hydrodynamic response and deduce the mooring line loads during a given typhoon event - typhoon Koppu in 2009 [17]. The significant wave height was recorded as $4.47 \mathrm{~m}$ with a peak wave period of $13.9 \mathrm{~s}$ and maximum sustained wind speed was $22.5 \mathrm{~m} / \mathrm{s}$. They found that the maximum mooring line tension during the passage of the typhoon was $F_{\max }=5064 \mathrm{kN}$ which is less than the maximum allowable tension, suggesting that the mooring system had the capability to endure typhoon conditions.

According to Liu et al [5], disaster prevention and mitigation for offshore structures, coastal regions and infrastructure in China needs to be improved in order to withstand the increasing frequency and intensity of typhoon events. Evidence suggests that the current design criteria is inadequate, a key consideration not commonly taken into account is the joint impact of typhoon induced storm surge, spring tides and flooding. In order to address this, Liu et al $[5,18]$ develop a multivariate compound extreme value distribution to provide design criteria for offshore structures and coastal infrastructure, considering the combined occurrence of such events. For example, in 2013 typhoon Fitow induced flood water levels of $5.15 \mathrm{~m}$ in the Yangtze River; however the existing China design code criteria recommended a 500 year return period water level of $4.8 \mathrm{~m}$ in this region. According to the coupled model in [5], this warning water level corresponds to less than a 50 year return period design value, and recommended instead a 100 year return period design value of $5.89 \mathrm{~m}$. The authors go on to provide a design criteria estimate for the elevation of a platform deck to be installed in the South China Sea, based on a 100 year return period and $\mathrm{H}_{\mathrm{s}}=5.95 \mathrm{~m}$. The prediction included a spring tide height of $2.45 \mathrm{~m}$, storm surge of $1.98 \mathrm{~m}$ and a wave crest height of $7.26 \mathrm{~m}$. Thus, this gives some indication of the amount of vertical extension that might be required of the mooring lines used to tether a wave energy converter in a similar region

\section{WAVE ENERGY RESEARCH IN CHINA}

Wave energy research and development in China has been undertaken since the late 1970's [19]. The WECs which have been developed and tested at sea fall into three main categories; oscillating water columns (OWCs), point absorbers and pendulum-type oscillating wave surge converters, a detailed review of which can be found in [3, 19-21].

Projects of various scales and power capacities have been installed, from $1 \mathrm{~kW}$ point absorbing lantern buoys used in ports and harbours to aid navigation [19], to a $30 \mathrm{~kW}$ pendulous WEC installed as part of a larger hybrid renewable power station on Daguan Island with a combined capacity of $100 \mathrm{~kW}$ [3]. During sea trials however, a number of these devices have failed having suffered damage inflicted by the impact of a typhoon, see $[20,21]$.

A number of OWCs of increasing capacity have been installed in the Guandong province. In 1989 a $3 \mathrm{~kW}$ prototype shoreline OWC wave power station was installed on Danwanshan Island, in the Pearl River estuary. Following its success, this was replaced in 1996 by a $20 \mathrm{~kW}$ plant, shown in Fig. 4(d), demonstrating the capacity of wave power to provide a reliable source of electricity to remote islands. A higher rated $100 \mathrm{~kW}$ shoreline OWC wave power plant was later installed in 2001 in Zhelang Town, Shanwei City [19]. These devices however have all been hampered by low efficiencies, limited by the operational efficiencies of the air turbines. The inertia of the turbine and generator is too high to match the large acceleration of the oscillating air flow [20]. 


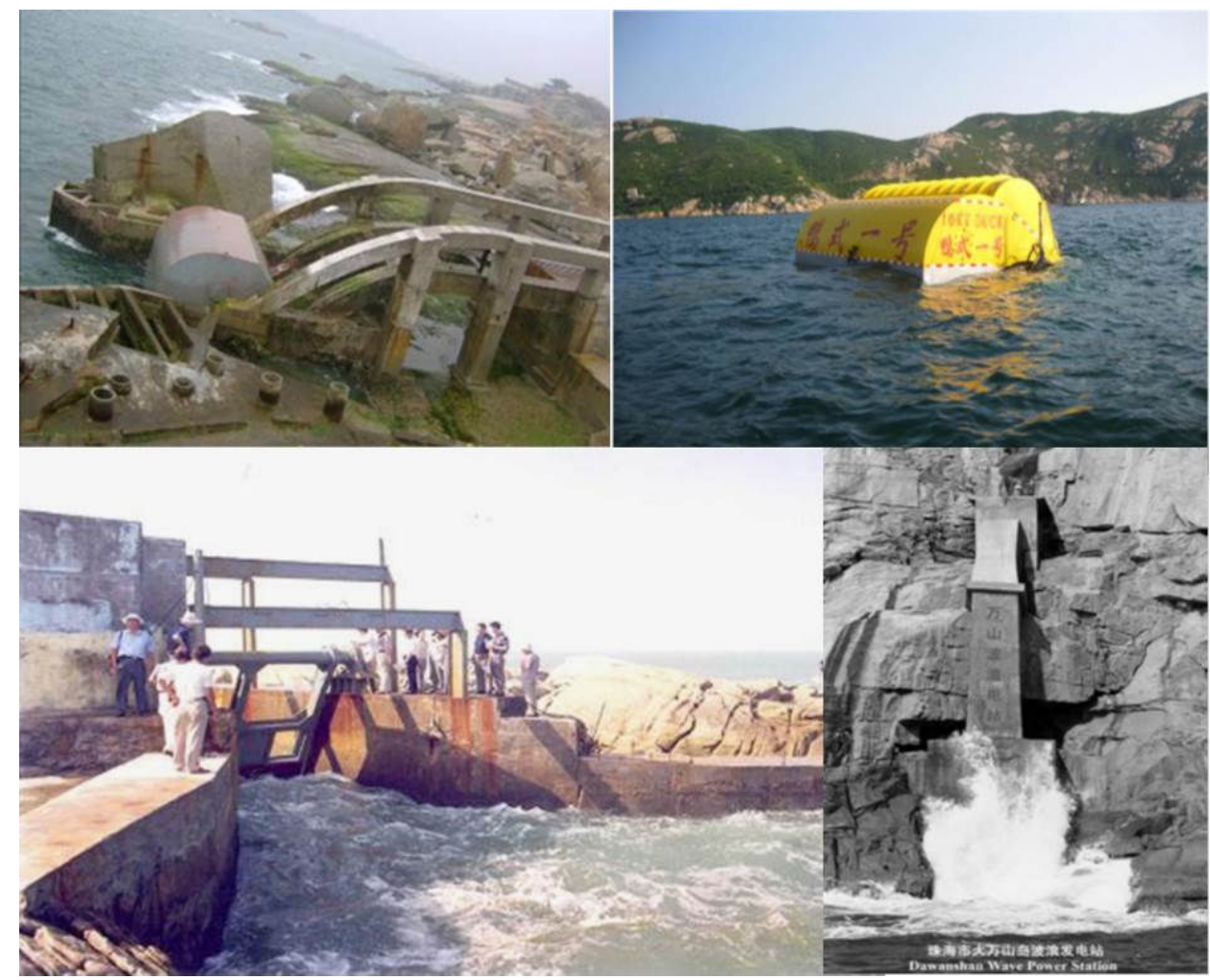

Figure 4: Wave energy devices tested and deployed in China; from top left, clockwise (a) Onshore 50kW oscillating buoy [23 D Zhang 2012 Ren Sus Rev]; (b) The $10 \mathrm{~kW}$ floating Duck during a sea trial [20 You et al Phil Trans A]; (c) The pendulous-WEC on Daguan Island [23 D Zhang 2012 Ren Sus Rev]; (d) Dawanshan Island 20 kW OWC [3 S Wang 2011].

An onshore oscillating buoy rated at $50 \mathrm{~kW}$ was trialled in 2006 by Guangzhou Institute of Energy Conversion; see Fig. 4(a). The device comprised a wheeled buoy which could oscillate up and down a concrete onshore slipway driving a system of hydraulic pumps. The buffered PTO of the buoy was found to deliver a far more stable conversion of hydraulic power to electrical output than a typical generator in the reciprocating airflow of an OWC. Acting as a terminator device it also had a relatively large capture width however, the device was found to be unreliable - after being in operation for 29 hours the device fell into the sea and eventually went missing during a typhoon 15 days later [20].

A nodding floating duck device, based Salter's original design, is also under development; Fig. 4(b) shows a 10 $\mathrm{kW}$ version of the device which was deployed in 2009 . The asymmetric duck is allowed to pitch about a horizontal cylindrical spine aligned perpendicular to the incoming waves. The potential high efficiency of such a device is attractive given the moderate wave energy densities in Chinese waters. You et al [20] highlight that a key requirement for the future advancement of the floating duck WEC is the development of a reliable mooring system, in particular ensuring the survival of the device during typhoons. A mooring system employing a floater-sinker design proposed and has been shown experimentally to significantly reduce the loads on the chain and anchor [20]. However this is a relatively complex and potentially costly design, due to the number of required elements and connectors..
In 1999 the National Ocean Technology Centre (NOTC) installed and operated a $8 \mathrm{~kW}$ pendulous WEC over two years. This was later rebuilt in 2008 and upgraded to a 30 $\mathrm{kW}$ installation, along with wind and solar energy conversion systems to meet the energy demands of the 120 residents of Daguan Island. The pendulous WEC falls into the category of an oscillating wave surge converters, see Fig. 4(c); a flap is hinged above the sea surface over the entrance of a contained volume of water and is forced back and forth by the incoming waves powering an electric pump and generator [3]. Other devices have also been deployed at Daguan Island for testing, for example a nearshore $100 \mathrm{~kW}$ inverted pendulum device was installed in 2012. It is a seabed mounted, bottom-hinged flap [21]. However despite surviving the extreme sea states of typhoon Davi, the hydraulic PTO was destroyed later that year in a second typhoon, typhoon Bravan.

More recently, the GIEC has developed and tested a 10 $\mathrm{kW}$ point absorber WEC that can be submerged to avoid extreme waves during a typhoon [22]. The device consists of a linear generator connected to a floating oscillating buoy which moves in heave relative to a submerged damping plate, relying on the tuning of resonances and damping to improve the efficiency of the device. In the wave tank conversion efficiencies of more than $40 \%$ have been measured, and during ocean trials the device obtained 8 days of electricity generation data. 


\section{MOORING SYSTEMS FOR PEAK LOAD MITIGATION}

Mooring systems for marine renewable energy technologies must satisfy four main design requirements.

- Survivability: maintain integrity in extreme load conditions

- Reliability: maintain integrity and functionality for specified lifetime

- Sustain given footprint / compliance

- Cost effectiveness

These mooring systems are typically derived from the offshore oil and gas industry but as described in [23, 24] they do require specific design considerations. In order to confidently ensure the survivability and reliability of the station keeping a high Minimum Breaking Load (MBL) is typically required, maintaining a high factor of safety (FOS). For conventional mooring designs this to either large mooring footprints or limited compliance. The mooring cost is proportional to the rated MBL [13]. If peak loads can be mitigated by novel mooring solutions, the mooring cost can be significantly reduced. The reduction of the design $\mathrm{MBL}$ will also reduce the cost for the structural design, connectors as well as deployment and installation cost.

The key mooring line design parameters that govern the design load is the mooring line stiffness. A number of systems are proposed to combine elastic and stiff mooring line characteristics that can potentially lead to reduction of the MBL. Proposed systems include the Seaflex buoy mooring system [25], the Exeter tether [26] and the TfI mooring tether [27, 28]. For the purpose of this paper a representative non-linear load response curve will be employed in an attempt to assess the feasibility of these novel mooring solutions for typhoon conditions.

For this paper the proprietary marine dynamics software OrcaFlex ${ }^{\circledR}$ from Orcina was used to estimate the mooring loads. The software employs a three-dimensional nonlinear time domain finite element code that solves the dynamic behaviour of line objects. It uses a lumped mass element approach that is in more detail described in [29].

\subsection{COMPUTATIONAL MODEL SETUP}

An initial numerical model was set up to assess the general feasibility in a first run of simulations.

\begin{tabular}{|c|c|}
\hline Parameter & Value \\
\hline Diameter & $10 \mathrm{~m}$ \\
\hline Height & $13 \mathrm{~m}$ \\
\hline Mass & $250 \mathrm{te}$ \\
\hline
\end{tabular}

Table 2: Design parameters for the 6 degree of freedom buoy in the numerical model
The computational model comprises the following elements:

- 6D Spar buoy: This object has all six degrees of freedom (DOF) and associated mass and moments of inertia. Hydrodynamic load calculations are based on Morison's equation, i.e. added mass and drag forces are computed for the submerged part of the buoy, see also Table 2 .

- Three mooring lines with a total length of $\mathrm{L}=57 \mathrm{~m}$ (see Fig. 5 and Fig. 6). The load response curve for the novel mooring tether is given in Fig. 7.

- Mooring connection points to 6D buoy

- Anchor points for individual mooring lines.

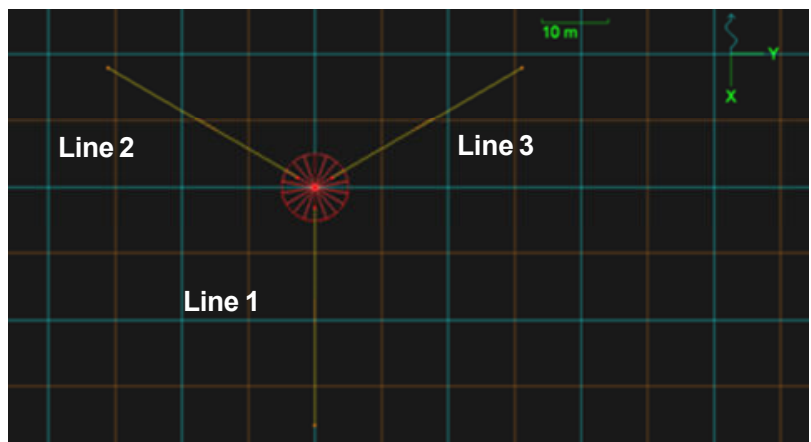

Figure 5: Mooring configuration (top view), incident waves are collinear to Line 1.

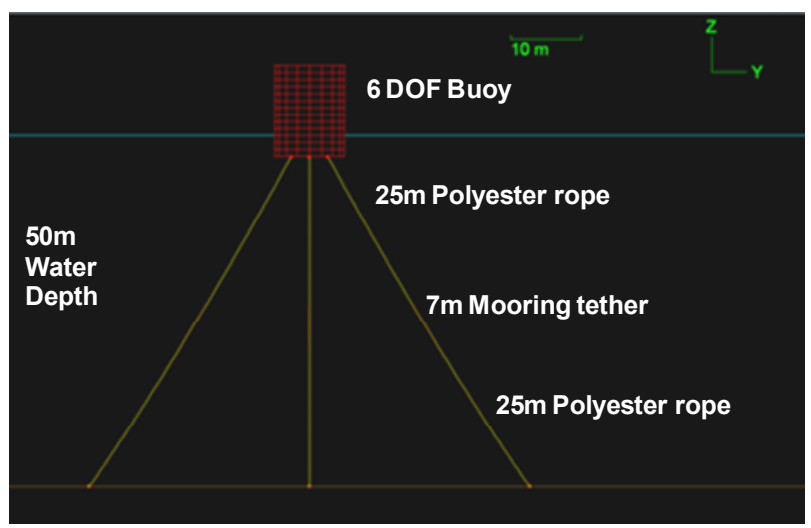

Figure 6: Mooring configuration, taut moored configuration in $50 \mathrm{~m}$ water depth, nonlinear mooring behaviour assigned to $7 \mathrm{~m}$ section of mooring thether.

To evaluate the effect of the novel mooring tether two scenarios were modelled at a range of environmental conditions.

- $\quad$ Reference case - $7 \mathrm{~m}$ section modelled as chain element

- Novel mooring tether - $7 \mathrm{~m}$ section modelled with non-linear load-response shown in Fig. 7. 


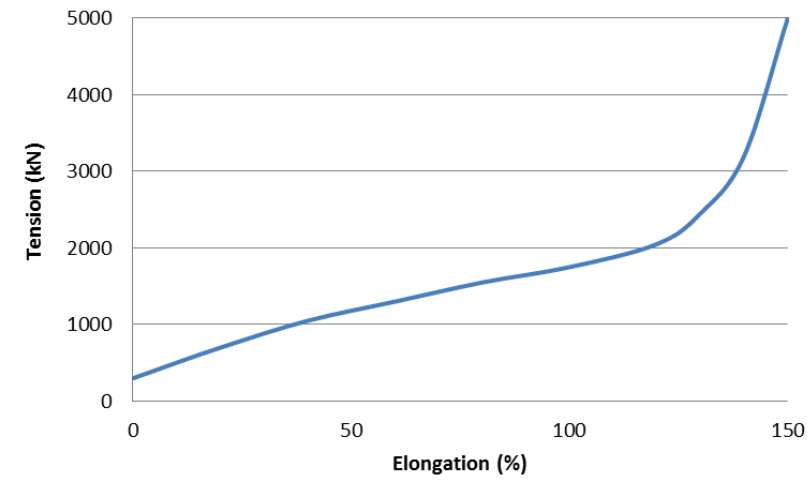

Figure 7. Load-elongation curve of mooring tether used in the numerical model with nonlinear axial stiffness.

\subsection{MODEL RESULTS}

The initial modelling showed promising results and will be briefly presented in the following. Two aspects are of particular interest, i) the max effective tension for mooring line 1 which withstands the highest loads in the modelled scenario and ii) heave displacement which will be relevant to ensure that sufficient power-takeoff is still possible for the heaving point absorber. The model results will be shown for a representative case in $\mathrm{Hs}=7 \mathrm{~m}$ and $\mathrm{T}=10 \mathrm{~s}$.

The maximum and mean effective tension along the length of mooring line 1 is plotted in Fig. 8. It shows that in the given case the novel mooring tether reduces the max tension from $833 \mathrm{kN}$ down to $663 \mathrm{kN}$ (at the top end), a reduction of $-20 \%$. The max tension slightly reduces along the length of the line. The mean tension is reduced by about $10 \%$.

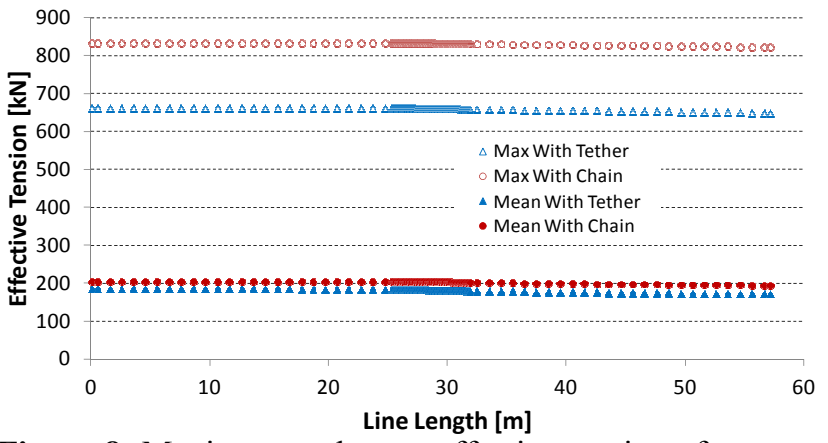

Figure 8: Maximum and mean effective tension of mooring line 1 . Plot shows the range graph, plotting the max. and mean tension during the simulation along the length of the line. Shown case: $\mathrm{H}_{\mathrm{s}}=7 \mathrm{~m}, \mathrm{~T}=10 \mathrm{~s}$.

The time series of the effective tension near the top end of mooring line 1 is plotted in Figure 9. It gives a direct comparison of the estimated forces and depicts how the largest peak loads are mitigated once the non-linear mooring characteristic is included. It is of importance for a wave energy point absorber, that the heave motion is not restrained, to maintain its ability for power production. Indeed the tether allows more heave motion than the chain in the shown case, compare Fig. 10.

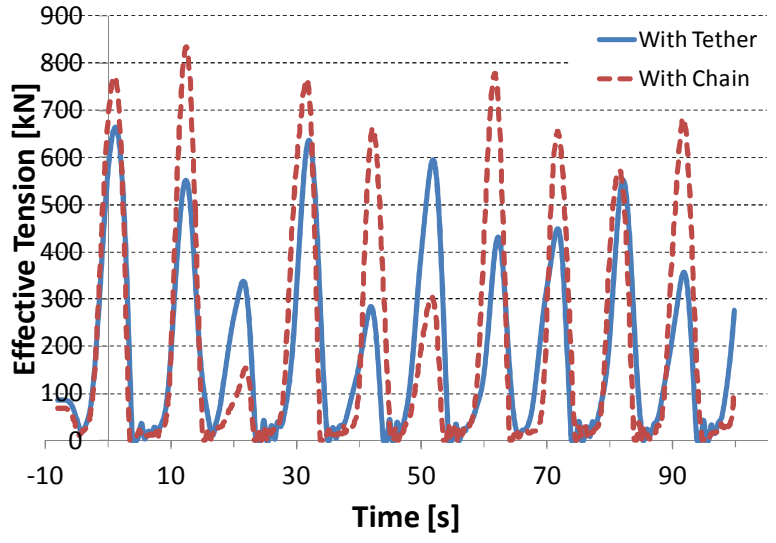

Figure 9: Time series of effective tension at the top end of mooring line 1. Shown case: $\mathrm{H}_{\mathrm{s}}=7 \mathrm{~m}, \mathrm{~T}=10 \mathrm{~s}$. Negative time values show build-up period.

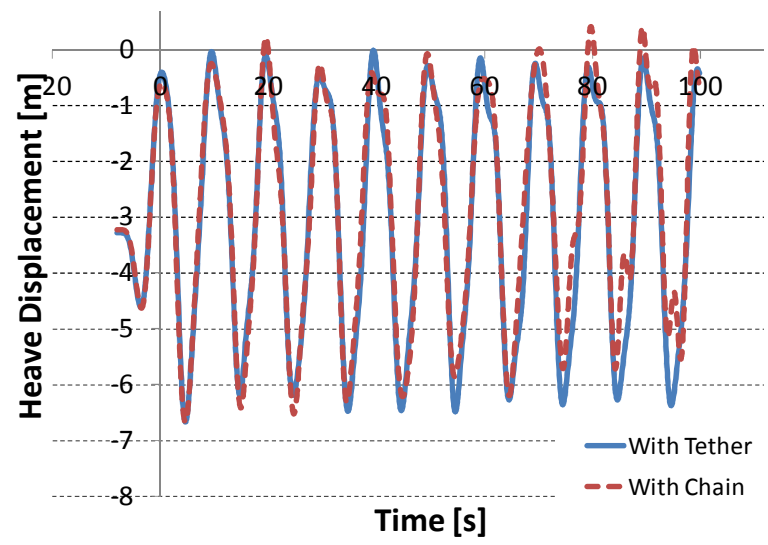

Figure 10: Time series of heave displacement of 6DOF buoy. Shown case: $\mathrm{H}_{\mathrm{s}}=7 \mathrm{~m}, \mathrm{~T}=10 \mathrm{~s}$. Negative time values show build-up period.

\section{CONCLUSIONS \& FURTHER WORK}

The paper has brought together the environmental conditions for typhoons in Chinese waters and the mooring design solutions that warrant the survivability and reliability in a cost effective manner. The initial results have shown promise that mooring components with non-linear load responses have potential to reduce the peak loads and subsequently lead to reduced MBL and cost of mooring systems. Further work as part of this collaborative effort is planned in the following aspects:

- To develop and implement a more accurately model of the wave energy point absorber device, developed by NOTC in collaboration with Harbin University

- To assess the sensitivity of mooring line tensions in respect to different environmental conditions, in particular in view of the different typhoon categories.

- Consideration of wind loads and current loads in the numerical model, to represent the locally very strong winds during typhoons.

- Optimisation of mooring line configurations, i.e. the stiffness, length and number of novel mooring tether in the individual lines. 
6.

\section{ACKNOWLEDGEMENTS}

This project was funded through the Newton Fund, administered by EPSRC, Grant Ref: EP/M019942/1. The Newton Fund is part of the UK's Official Development Assistance (ODA). Its aim is to develop science and innovation partnerships that promote the economic development and welfare of developing countries. The support is gratefully acknowledged. The software provision by Orcina is also acknowledged.

\section{REFERENCES}

1. CW Zheng, $\mathrm{H}$ Zhuang, $\mathrm{X}$ Li and XQ Li 'Wind energy and wave energy resources assessment in the East China Sea and South China Sea'. Science China Technological Sciences 55(1):163-173, 2012.

2. P Zhang, Y Yang, Shi jin, Y Zheng, L Wang and X Li. 'Opportunities and challenges for renewable energy policy in China'. Renewable and Sustainable Energy Reviews 13 (2): 439-449, 2009.

3. S Wang, P Yuan, D Li, Y Jiao, 'An overview of ocean renewable energy in China', Renewable and Sustainable Energy Reviews, 15: 91 - 111, 2011

4. .Joint Typhoon Warning Center. '2011 Annual Tropical Cyclone Report: Western Pacific'. United States Navy, United States Air Force, 2011. Available online from http://www.usno.navy.mil/NOOC/nmfe$\mathrm{ph} / \mathrm{RSS} / \mathrm{jtwc} / \mathrm{atcr} / 2011$ atcr.pdf

5. D Liu, L Pang and A Xie. Typhoon disaster in China: prediction, prevention \& mitigation. Natural Hazards. 49:421-436, 2009

6. CW Zheng, J Pan and JV Lia 'Assessing the China Sea wind energy and wave energy resources from 1988 to 2009'. Ocean Engineering 65: 39-48, 2013

7. S Wu, C Liu, X Chen. 'Offshore wave energy resource assessment in the East China Sea' Renewable Energy 76: 628-636, 2015.

8. JCC van Nieuwkoop, HCM Smith, GH Smith and L Johanning. "Wave resource assessment along the Cornish coast (UK) from a 23-year hindcast dataset validated against buoy measurements'. Renewable Energy, 58: 1-14, 2013.

9. J Yin, Z Yin and $\mathrm{S} \mathrm{Xu.} \mathrm{'Composite} \mathrm{risk} \mathrm{assessment}$ of typhoon-induced disaster for China's coastal area'. Natural Hazards, 69:1423-1434, 2013.

10. J Lin, DL Tang, W Alpers and S Wang. Response of dissolved oxygen and related marine ecological parameters to a tropical cyclone in the South China
Sea. Advances in Space Research, 53(7): 1081-1091, 2014

11. YG Zheng, J Chen and Z Tao. 'Distribution Characteristics of the Intensity and Extreme Intensityof Tropical Cyclones Influencing China'. Journal of Meteorological Research. 28(3):393-406, 2014

12. GM Zheng and DL Tang. Offshore and nearshore chlorophyll increases induced by typhoon winds and subsequent terrestrial rainwater runoff. Marine Ecology Progress Series, 333, 61-74, 2007.

13. RE Harris, L Johanning and J Wolfram. 'Mooring system for wave energy converters: A review of design issues and choices'. Proc. of the $3^{\text {rd }}$ International Conference on Marine Renewable Energy, Blyth, 2004.

14. Carbon Trust Report. 'Appraisal of the Offshore Wind Industry in Japan'. 2014 Available online from http://goo.gl/Otk0r8

15. T Utsunomiya, I Sato, $\mathrm{T}$ Shiraishi, E Inui and $\mathrm{S}$ Ishida. 'Floating Offshore Wind Turbine Demonstration Project at Goto Islands, Japan'. Proc. of OCEANS 2014, Taipei, 2014

16. H Liu, D Li, XP Bai, JP Wang, BL Zhang. 'Research and design on internal turret mooring system of FPSO in South China Sea'. Proc of the $33^{\text {rd }}$, International Conference on Ocean, Offshore and Artcic Engineering, OMAE 2014, San Francisco, 2014

17. WH Zhao, JM Yang, ZQ Hu and YF Wei. 'Full-scale measurement investigation of the hydrodynamics of a turret-moored FPSO in a typhoon and deduction of its mooring loads' Ships and Offshore structures 7(3):285-295, 2011.

18. D Liu, G Liu, H Shi, F Wang, Z Chen. 'Extreme Sea Hazards Statistics and Engineering Applications', Proc. of OCEANS 2014, Taipei, 2014

19. D Zhang, W Li, Y Lin, 'Wave energy in China: Current status and perspectives', Renewable Energy, 34: 2089 - 2092 (2009)

20. YG You, SW Sheng, BJ Wu, YQ He, 'Wave energy technology in China', Phil. Trans. R. Soc. A, 370: 472-480, 2012

21. C Ma, Y Gao, D Xia, C Wang, 'Wave Energy in China Priority and synergy towards the demonstration of WECs', Proc. $10^{\text {th }}$ European Wave and Tidal Energy Conference EWTEC, Aalborg, 2013 
22. BJ Wu, XH Diao, KL Wang, YG You, YQ Zhang, W Peng, Y Xiao, GB Hu, HY Jia, J Chen, '10kW Floating Direct Drive Wave Energy Converter in GIEC', Proc. $10^{\text {th }}$ European Wave and Tidal Energy Conference EWTEC, Aalborg, 2013

23. L Johanning, GH Smith, J Wolfram, 'Mooring design approach for wave energy converters', Proc Inst Mech Eng, Part M: J Eng Marit Environ 220:159-174, 2006.

24. L Johanning, GH Smith, J Wolfram, 'Measurements of static and dynamic mooring line damping and their importance for floating WEC devices', Ocean Engineering 34:1918-1934, 2007.

25. N Bengstsson and V Ekstrom. 'Sea Flex - the buoy mooring system: Increase life cycle and decrease cost for navigation buoys', 2010. Available online from http://buoymooring.com/data/archive/WhitePaper-SEAFLEX-Buoy-Mooring.pdf

26. T Gordelier, D Parish, Johanning L, and PR Thies. 'A novel mooring tether for highly dynamic offshore applications; mitigating peak and fatigue loads via selectable axial stiffness'. Proc. of the International Conference on Offshore Renewable Energy, Glasgow, 2014.

27. P Mc Evoy. 'Combined elastomeric \& thermoplastic mooring tethers'. Proc. of 4th International Conference on Ocean Energy, Dublin, 2012.

28. PR Thies, L Johanning and P McEvoy. A novel mooring tether for peak load mitigation: Initial performance and service simulation testing. International Journal of Marine Energy 7:43-56, 2014.

29. Orcina. OrcaFlex manual, Version 9.7a, 2013, available from www.orcina.com

\section{AUTHORS BIOGRAPHY}

Dr Philipp Thies is a Lecturer in Renewable Energy at the University of Exeter. His research focuses on reliability engineering for offshore renewable energy. His expertise spans the numerical and experimental analysis of critical marine energy components, including dynamic marine cables and mooring systems.

Dr Sarah Crowley is a Research Fellow in Offshore Renewable Energy at the University of Exeter. Her research lies in the area of liquid sloshing and coupled resonant systems, in particular with application to tuned liquid dampers and ocean wave energy extraction.

Prof Lars Johanning is Assistant Professor in Ocean Energy and is the academic lead of the Renewable Energy group at the University of Exeter. He has leading roles in the international research community in the field of mooring systems, reliability and marine operations for offshore renewable energy devices.

Dr Haijun Ye is Assistant Professor of remote sensing of marine biology at the South China Sea Institute of Oceanography. His research interests lie in the area of Phytoplankton size classes, remote sensing and responses to typhoons.

Prof DanLing Tang is Professor of remote sensing of marine ecology and the oceanic environment at the South China Sea Institute of Oceanography. Her major research interests include ocean dynamics of phytoplankton blooms, global environmental changes, and the impacts of natural hazards on the marine ecosystem.

Lin Cui is a Senior Scientist at the National Ocean Technology Center, China. His research focus is the design, development and operational assessment of wave energy conversion systems, including the numerical and physically modelling of converters, optimisation of the power take-off and system monitoring.

Dr Xuelin Li works as a research assistant at the National Ocean Technology Center, China. His research interests are the performance and survivability assessment for marine energy conversion systems. He participates in the formulation and the design of the National Test Sites for wave and tidal current energy converters in China. 